\title{
Pivotal role of the renin/prorenin receptor in angiotensin II production and cellular responses to renin
}

\author{
Genevieve Nguyen, ${ }^{1}$ Françoise Delarue, ${ }^{1}$ Céline Burcklé, ${ }^{1}$ Latifa Bouzhir, ${ }^{1}$ Thomas Giller, ${ }^{2}$ \\ and Jean-Daniel Sraer ${ }^{1}$
}

${ }^{1}$ Institut National de la Santé et de la Recherche Médicale (INSERM) U489, and Association Claude Bernard, Hopital Tenon, Paris, France

${ }^{2}$ Hoffman-La Roche Ltd., Basel, Switzerland

Address correspondence to: Genevieve Nguyen, INSERM U489, Hopital Tenon, 4 rue de la Chine, 75020, Paris, France. Phone: (331) 560183 17; Fax: (331) 436454 48; E-mail: genevieve.nguyen@tnn.ap-hop-paris.fr.

Latifa Bouzhir's present address is: INSERM U451, Ecole Polytechnique-ENSTA, Palaiseau, France.

Thomas Giller's present address is: AXOVAN Ltd. Innovation Center, Allschwil, Switzerland.

Received for publication September 24, 2001, and accepted in revised form April 22, 2002.

Renin is an aspartyl protease essential for the control of blood pressure and was long suspected to have cellular receptors. We report the expression cloning of the human renin receptor complementary DNA encoding a 350-amino acid protein with a single transmembrane domain and no homology with any known membrane protein. Transfected cells stably expressing the receptor showed renin- and prorenin-specific binding. The binding of renin induced a fourfold increase of the catalytic efficiency of angiotensinogen conversion to angiotensin I and induced an intracellular signal with phosphorylation of serine and tyrosine residues associated to an activation of MAP kinases ERK1 and ERK2. High levels of the receptor mRNA are detected in the heart, brain, placenta, and lower levels in the kidney and liver. By confocal microscopy the receptor is localized in the mesangium of glomeruli and in the subendothelium of coronary and kidney artery, associated to smooth muscle cells and colocalized with renin. The renin receptor is the first described for an aspartyl protease. This discovery emphasizes the role of the cell surface in angiotensin II generation and opens new perspectives on the tissue renin-angiotensin system and on renin effects independent of angiotensin II.

J. Clin. Invest. 109:1417-1427 (2002). doi:10.1172/JCI200214276.

\section{Introduction}

The renin-angiotensin system (RAS) is critical for the control of blood pressure and salt balance in mammals. Renin is an aspartyl protease synthesized as prorenin, a proenzyme that contains an additional 43-amino acid $\mathrm{N}$-terminal fragment. The physiological maturation of prorenin into active renin takes place exclusively in the juxtaglomerular cells of the kidney (1). Renin has high substrate specificity, and its only known substrate is angiotensinogen. Renin cleaves the $\mathrm{N}$ terminus of circulating angiotensinogen to angiotensin I (Ang I; a decapeptide), which is then transformed in angiotensin II (Ang II; an octapeptide) by soluble or endothelial cell-associated angiotensin-converting enzyme (ACE). In the heart, the majority of Ang I is converted by chymase (2). The rate-limiting step in the RAS is Ang I generation, even though the major biologically active peptide is Ang II. Ang II acts on vascular smooth muscle cells as a potent vasoconstrictor via Ang II receptors. These receptors are widely distributed and expressed by many cell types (3). Components of the RAS and Ang II receptors are found in the brain (4) and in many peripheral tissues such as the heart (5) and kidney (6), but also placenta (7), testis (8), adipose tissue (9), and eye $(10,11)$. Recent studies have shown that the RAS is involved in diverse physiological and pathological processes such as growth and remodeling (12), development (13), inflam- mation (14), vascular hypertrophy, and thrombosis (15). If Ang II and Ang IV receptors are well characterized, the demonstration of a functional renin receptor is still missing. Several proteins able to bind renin have been reported. The widely distributed mannose-6-phosphate receptor has been shown to bind renin and prorenin on rat cardiac myocytes (16) and on human endothelial cells (17). Another renin-binding protein called RnBp has been identified in rat, porcine, and human tissues and was shown later to be identical to the $N$-acyl-D-glucosamine 2-epimerase (18). Several binding sites have also been described on membranes from different rat organs but no functional effects of renin binding were reported $(19,20)$. In contrast to these studies $(19,20)$, we have shown that renin could bind to human mesangial cells in culture and that the binding induced an hypertrophic effect and an increase of plasminogen activator inhibitor-1. Renin bound to the receptor was neither internalized nor degraded $(21,22)$.

The receptors of proteases may play several roles. They serve to focus the enzymatic activity on a cell surface or at a cell-extracellular matrix interface, as for urokinase and plasminogen/plasmin (23). The urokinase receptor binds not only the active enzyme but also the inactive proenzyme. The binding of the proenzyme induces a conformational change that unmasks the active site in the absence of proteolytic activation of the proform. 
The receptor-bound enzyme has a much more efficient catalytic activity on the substrate (24). The receptor of a protease may also activate an intracellular signaling pathway leading to a change of cell phenotype and proliferation, as for the receptors of urokinase (25) and thrombin (26).

In this report we describe the identification of a renin receptor by expression cloning. Transfection of renin receptor cDNA into cells lacking specific binding of renin results in the expression of a $45-\mathrm{kDa}$ membrane protein that specifically binds renin and prorenin. The binding of renin to its receptor induces: (a) an increase of the catalytic efficiency of angiotensinogen conversion into Ang I by renin bound to the receptor compared with renin in soluble phase, and (b) a rapid phosphorylation of the receptor on serine and tyrosine residues associated with an activation of MAP kinases ERK1 and ERK2. Immunofluorescence and confocal analyses on normal human kidney and cardiac biopsies show that the receptor is localized within the mesangial area of glomeruli and in the subendothelium of kidney and coronary artery. Double-staining with antirenin and anti-smooth muscle $\alpha$-actin showed that, in the arteries, the receptor is present on smooth muscle cells. Furthermore, the staining of mature fetal placenta showed that renin and the receptor were colocalized in vascular structures and in syncytiotrophoblast cells.

Taken together, our results provide evidence for the existence of a functional renin receptor. This receptor is responsible for renin cellular effects, independent of the generation of Ang II. On the other hand, by increasing the efficiency of angiotensinogen cleavage by membrane-bound renin, this receptor also plays a role in the renin effects dependent on Ang II generation.

\section{Methods}

Reagents. Human recombinant renin, prorenin (27), and the polyclonal $\mathrm{Ab}$ to human renin were a gift of Walter Fischli (Hoffmann-La Roche Ltd., Basel, Switzerland). The polyclonal $\mathrm{Ab}$ to Ang I was a gift from Jean-Baptiste Michel (INSERM U460, Paris, France).

Expression cloning and 5' rapid amplification of cDNA ends $P C R$. A human kidney cDNA-phage library (CLONTECH Laboratories Inc., Palo Alto, California, USA) was screened with ${ }^{125}$ I-renin. Twelve positive clones were subcloned in pGEM-T Easy Vector (Promega Corp., Madison, Wisconsin, USA) and sequenced. One clone, N14F (GenBank accession number: AF291814), was selected, and $5^{\prime}$ rapid amplification of cDNA ends (RACE) was performed using the $5^{\prime}$ RACE PCR kit of Life Technologies Inc. (Rockville, Maryland, USA). Specific RT was performed on polyA ${ }^{+}$mRNA from primary mesangial cells with the antisense primer 5 -GAGCGTCAACAAGGATCTTAGAA-3' complementary to nucleotides 785-819. Nested PCR was done using the antisense primers $5^{\prime}$ GGGGGAGTGAACTGAGAACA- $3^{\prime}$ and $5^{\prime}$-GCATTCTCCAAAGGGTACGA-3' complementary to nucleotides 577-597 and 371-391. The nucleotide and the deduced amino-acid sequences were analyzed using NetPhos 2.0 prediction server (Center for Biological Sequence Analysis, Technical University of Denmark, Copenhagen, Denmark) and PSORT II prediction server (prediction of protein sorting signals and localization sites in amino acid sequence, Human Genome Center, Institute of Medical Science, University of Tokyo, Japan).

In vitro translation of $N 14 F$ and coprecipitation experiments. The coding region of N14F with the FLAG tag was translated in vitro (TnT-Coupled Reticulocyte Lysate; Promega Corp.) in the presence of ${ }^{35} \mathrm{~S}$-methionine and was analyzed by SDS-PAGE and fluorography. For coprecipitation experiments, the translated product was incubated with $25 \mathrm{nM}$ renin for 2 hours at $37^{\circ} \mathrm{C}$ and precipitated with anti-renin $\mathrm{Ab}$ and protein G-Sepharose (Sigma-Aldrich, St. Louis, Missouri, USA). The proteins were eluted and analyzed by SDSPAGE and fluorography.

Transfection of mesangial cells and renin-binding assay. A human fetal mesangial cell line (HMC) (28) that did not express N14F either by PCR or Northern blot analysis was selected and transfected by the Fugene method (Roche Diagnostics, Meylan, France) and with the coding region of N14F subcloned in pcDNA 3.1 Zeo (Promega Corp.) tagged at the $3^{\prime}$ end with the FLAG peptide (Asp-Tyr-Lys-Asp-Asp-Asp-Asp-Lys) by PCR, introducing GACTACAAGGACGACGATGACAAG before the stop codon. Stable transformants were selected with Zeocine. Two clones, HMC2 and HMC4, were selected. The binding experiments were performed as described (21), and the results were analyzed by the Scatchard method.

Ang I generation by cell-associated renin and prorenin or in soluble phase. Membranes from HMC and HMC2 were prepared as described (21). Five or ten micrograms of membrane was incubated with $5 \mathrm{nM}$ renin for 1 hour at $37^{\circ} \mathrm{C}$. After washing, the membranes were resuspended in $10 \mu \mathrm{l} \mathrm{Krebs} \mathrm{buffer} \mathrm{containing} 2 \%$ BSA and incubated 1 hour at $37^{\circ} \mathrm{C}$ with increasing concentrations $(1 \mathrm{nM}-1$ $\mu \mathrm{M})$ of angiotensinogen (Sigma-Aldrich) in $110 \mu \mathrm{l}$ acetate buffer, pH 5.7. The membranes were centrifuged, and the supernatant was assayed for Ang I (29). At the end of the incubation time, aliquots of membranes were treated with $100 \mathrm{mM}$ glycin buffer, $\mathrm{pH} 3.5$, and the renin eluted was measured with the Renin III Generation kit (Bio-Rad Laboratories Inc., Hercules, California, USA). Identical amounts of renin in solution were incubated alone or with $10 \mu \mathrm{g}$ of HMC membranes together with angiotensinogen. Similar experiments were performed with prorenin bound to HMC2 membranes or in solution, except the incubation was performed in Kreb's buffer, $\mathrm{pH}$ 7.4, for 4 hours to prevent a possible activation of prorenin. These experimental conditions were determined previously for fully active renin to obtain identical Ang I generation by renin incubated in buffer at $\mathrm{pH} 5.7$ and $\mathrm{pH}$ 7.4. Experiments with prorenin were performed twice in duplicate.

Analysis of the receptor expressed by transfected cells and cross-linking with renin. Control cells and HMC2 cells were metabolically labeled with ${ }^{35} \mathrm{~S}$-methionine for 24 
hours, lysed with $10 \mathrm{mM}$ Tris buffer, pH 8.0, $140 \mathrm{mM}$ $\mathrm{NaCl}$ (TSA) containing Triton X-100 1\%, 1 mM PMSF, $500 \mathrm{U} / \mathrm{ml}$ aprotinin (TSA-TX). The receptor was immunoprecipitated, and the proteins eluted were analyzed by SDS-PAGE and fluorography. For cross-linking experiments, the cells were incubated with or without $25 \mathrm{nM}$ renin for 1 hour at $37^{\circ} \mathrm{C}$ and cross-linked as described (21). The cells were lysed, and the reninreceptor complex was immunoprecipitated with antireceptor $\mathrm{Ab}$. The proteins eluted were analyzed by SDSPAGE and fluorography.

Intracellular free $\left[\mathrm{Ca}^{2+}\right]$ and cyclic AMP changes induced by renin. Briefly, subconfluent cells in a $10-\mathrm{mm}$ Petri dish were loaded with $5 \mu \mathrm{M}$ Fura- 2 for 45 minutes at $37^{\circ} \mathrm{C}$, washed, and detached by mild trypsinization. Cells were resuspended in PBS buffer containing 1\% BSA and transferred into a quartz cuvette under constant stirring at $37^{\circ} \mathrm{C}$. Fluorescence was monitored in a Quanta Master 1 spectrofluorometer, and $\left[\mathrm{Ca}^{2+}\right]$ was calculated using Felix 1.1 software program (Photon Technology International, Brunswick, New Jersey, USA).

For cAMP study, cells in 24-well plates were serum deprived for 18 hours and incubated 30 minutes in culture medium containing $100 \mu \mathrm{M}$ isobutyl-methyl-xanthine. After addition of $10 \mathrm{nM}$ renin or $1 \mu \mathrm{MPGE} \mathrm{P}_{2}$ or 1 $\mu \mathrm{M}$ of isoproterenol, the reaction was stopped after 5 minutes by addition of $250 \mu \mathrm{l}$ of ethanol $95 \%$-formic acid $5 \%$. The supernatant was evaporated overnight, and the cAMP content of each well was measured with cAMP[125I] assay (Amersham Pharmacia Biotech, Piscataway, New Jersey, USA). Measurements of cAMP activity were made two times in triplicate, and statistical analysis was performed using the Wilcoxon nonparametric test.

Analysis of the pattern of the receptor phosphorylation and MAP kinases ERK1/ERK2 activation induced by renin. HMC2 cells were incubated with $10 \mathrm{nM}$ renin for 0,3 , and 10 minutes and in the presence of $100 \mathrm{nM}$ Captopril. The cells were lysed with TSA-TX containing $2 \mathrm{mM}$ $\mathrm{Na}_{3} \mathrm{VO}_{4}, 50 \mathrm{mM} \mathrm{NaF}$, and $5 \mathrm{mM}$ EDTA. The receptor was immunoprecipitated with anti-FLAG agarose. Bound proteins were analyzed by Western blotting with anti-phosphotyrosine (Chemicon International, Temecula, California, USA), anti-phosphoserine, or anti-phosphothreonine Ab's (Sigma-Aldrich) and revealed by the ECL kit (Amersham Pharmacia Biotech). Control cells were incubated with renin, lysed, and analyzed by Western blotting with anti-phosphotyrosine and anti-phosphoserine Ab's without prior immunoprecipitation of the receptor with anti-FLAG agarose.

To study MAP kinases ERK1 (p44) and ERK2 (p42) activation, cells were serum deprived for 18 hours and stimulated with $10 \mathrm{nM}$ renin for various times in the presence of $1 \mu \mathrm{M}$ Losartan. The cells were lysed with 100 $\mu \mathrm{l}$ lysis buffer as described. Proteins were measured with the Bio-Rad Laboratories Inc. $D C$ protein assay and analyzed by Western blotting using Ab's to total and active ERK1/ERK2 (Promega Corp.) and revealed by the ECL kit. The blots were scanned and plotted to obtain a bar graph representation of the ratio of active-to-total
ERK1/ERK2 activation using the NIH IMAGE program (Bethseda, Maryland, USA). To confirm MAP kinases ERK1/ERK2 activation, MAP kinase activity of cell lysate was also measured using the Biotrak $\mathrm{p} 42 / \mathrm{p} 44$ MAP kinase enzyme assay system (Amersham Pharmacia Biotech). Measurements of MAP kinase activity were made two times in triplicate, and statistical analysis was performed using the Wilcoxon nonparametric test.

Northern blot analysis. A cDNA fragment containing the Not1-Xba1 coding region of N14F subcloned into pcDNA 3.1 was radiolabeled (PrimeIt labeling kit; Stratagene, La Jolla, California, USA) and hybridized to a membrane containing the polyA ${ }^{+}$mRNA from human tissues (CLONTECH Laboratories Inc.). The amount of RNA was adjusted so that the $\beta$-actin hybridization signal was of comparable intensity in every lane. The blots were hybridized and washed using ExpressHyb (CLONTECH Laboratories Inc.).

Immunofluorescence studies on transfected cells, on buman normal kidney and heart, and on mature placenta. Rabbits were immunized by coinjection of synthetic peptides corresponding to amino acids $221-235$ and $337-350$ of the receptor (Eurogentec SA, Herstal, Belgium). Specimens of kidney and heart were obtained from the operating room after total nephrectomy for tumor and during mitral valve replacement, respectively, with informed consent of the patient. Mature placenta was obtained from the delivery room, with informed consent of the patient. Permeabilized cells and the cryopreserved tissues were fixed in $4 \%$ paraformaldehyde and incubated with rabbit antiserum to the receptor (1:1,000 dilution) with mAb's to CD31 or to smooth muscle $\alpha$-actin (Sigma-Aldrich). FITC or Texas red (TRITC) secondary $A b$ 's were used to visualize the staining. The specificity of the staining for the renin receptor was assessed by preincubation of the primary $\mathrm{Ab}$ with the peptides. To study the colocalization of renin and renin receptor, staining was performed on sequential sections of placenta using the polyclonal $\mathrm{Ab}$ to the receptor $(1: 1,000$ dilution) revealed by FITC-secondary anti-rabbit Ig or the polyclonal $\mathrm{Ab}$ to human renin (1:50 dilution) revealed by TRITC-secondary anti-rabbit Ig.

\section{Results}

Expression cloning of renin receptor. We have screened $1,000,000$ clones of a commercial human kidney expression library in $\lambda$ gt 11 with recombinant human renin labeled with ${ }^{125}$. The positive clones were amplified by PCR using $\lambda$ gt 11 primers and subcloned in PGEM-T Easy for sequencing. The sequence of one clone (N14F, $2,034 \mathrm{bp}$ ) represented a new protein with no homology with any known membrane-receptor family (Figure 1a). The initiation codon was surrounded by the optimal Kozak nucleotide consensus sequence (GCCACC), and the open reading frame encoded a 350-amino acid protein (molecular weight $39.008 \mathrm{kDa}$ ). The integrity of the $5^{\prime}$ end was assessed by rapid amplification of complementary cDNA $5^{\prime}$ end by PCR and by comparison with an expressed sequence tag data base. The deduced 

GCCCGTGTCCGCCGGCCGTTCCTGTCGCCGCGTACCTCCTCACGCTGCGGCTGT $* * *$ ATGGCTGTGTTTGTCGTGCTCCTGGCGTTGGTGGCGGGTGTTTTGGGGAACGAGTTTAGT 60 ATATTAAAATCACCAGGGTCTGTTGTTTTCCGAAATGGAAATTGGCCTATACCAGGAGAG 120 CGGATCCCAGACGTGGCTGCATTGTCCATGGGCTTCTCTGTGAAAGAAGACCTTTCTTGG 180 CCAGGACTCGCAGTGGGTAACCTGTTTCATCGTCCTCGGGCTACCGTCATGGTGATGGTG 240 AAGGGAGTGAACAAACTGGCTCTACCCCCAGGCAGTGTCATTTCGTACCCTTTGGAGAAT 300 GCAGTTCCTTTTAGTCTTGACAGTGTTGCAAATTCCATTCACTCCTTATTTTCTGAGGAA 360 ACTCCTGTTGTTTTGCAGTTGGCTCCCAGTGAGGAAAGAGTGTATATGGTAGGGAAGGCA 420 AACTCAGTGTTTGAAGACCTTTCAGTCACCTTGCGCCAGCTCCGTAATCGCCTGTTTCAA 480 GAAAACTCTGTTCTCAGTTCACTCCCCCTCAATTCTCTGAGTAGGAACAATGAAGTTGAC 540 CTGCTCTTTCTTTCTGAACTGCAAGTGCTACATGATATTTCAAGCTTGCTGTCTCGTCAT 600 AAGCATCTAGCCAAGGATCATTCTCCTGATTTATATTCACTGGAGCTGGCAGGTTTGGAT $\quad 660$ GAAATTGGGAAGCGTTATGGGGAAGACTCTGAACAATTCAGAGATGCTTCTAAGATCCTT 720 GTTGACGCTCTGCAAAAGTTTGCAGATGACATGTACAGTCTTTATGGTGGGAATGCAGTG 780 GTAGAGTTAGTCACTGTCAAGTCATTTGACACCTCCCTCATTAGGAAGACAAGGACTATC 840 CTTGAGGCAAAACAAGCGAAGAACCCAGCAAGTCCCTATAACCTTGCATATAAGTATAAT 900 TTTGAATATTCCGTGGTTTTCAACATGGTACTTTGGATAATGATCGCCTTGGCCTTGGCT 960 GTGATTATCACCTCTTACAATATTTGGAACATGGATCCTGGATATGATAGCATCATTTAT 1020 AGGATGACAAACCAGAAGATTCGAATGGATTGA ATGTTACCTGTGCCAGAATTAGAAAAG 1080

GGGGTTGGAAATTGGCTGTTTTGTTAAAATATATCTTTTAGTGTGCTTTAAAGTAGATAG TATACTTTACATTTATAAAAAAAAATCAAATTTTGTTCTTTATTTTGTGTGTGCCTGTGA TGTTTTTCTAGAGTGAATTATAGTATTGACGTGAATCCCACTGTGGTATAGATTCCATAA TATGCTTGAATATTATGATATAGCCATTTAATAACATTGATTTCATTCTGTTTAATGATT TTGGAAATATGCACTGAAAGAAATGTAAAACATTTAGAATAGCTCGTGTTATGGAAAAAA 1380 GTGCACTGAATTTATTAGACAAACTTACGAATGCTTAACTTCTTTACACAGCATAGGTGA 1440 AAATCATATTTGGGCTATTGTATACTATGAACAATTTGTAAATGTCTTAATTTGATGTAA 1500 ATAACTCTGAAACAAGAGAAAAGGTTTTTAACTTAGAGTAGCCCTAAAATATGGATGTGC 1560 TTATATAATCGCTTAGTTTTGGAACTGTATCTGAGTAACAGAGGACAGCTGTTTTTTAAC 1620 CCTCTTCTGCAAGTTTGTTGACCTACATGGGCTAATATGGATACTAAAAATACTACATTG 1680 ATCTAAGAAGAAACTAGCCTTGTGGAGTATATAGATGCTTTTCATTATACACACAAAAAT 1740 CCCTGAGGGACATTTTGAGGCATGAATATAAAACATTTTTATTTCAGTAACTTTTCCCCC 1800 TGTGTAAGTTACTGTGGTTTGTGGTACAACTTCATTCTATAGAATATTAAGTGGAAGTGG 1860 GCGAATTCTACTTTTTATGTTGGAGTGGACCAATGTCTATCAAGAGTGACAAATAAAGTT 1920 AATGATGATTCCAAAAAAAAAAAAA
MAVFVLLALVAGVLGNEFSILKSPGSVVFRNGNWPIPGERIPDVAALSMGFSVKEDLSW PGLAVGNLFHRPRATVMVMVKGVNKLALPPGSVISYPLENAVPFSLDSVANSIHSLFSEE TPVVLQLAPSEERVYMVGKANSVFEDLSVTLRQLRNRLFQENSVLSSLPLNSLSRNNEVD LLFLSELQVLHDISSLLSRHKHLAKDHSPDLYSLELAGLDEIGKRYGEDSEQFRDASKIL VDALQKFADDMYSLYGGNAVVELVTVKSFDTSLIRKTRTILEAKQAKNPASPYNLAYKYN FEYSWVN MVLWIMIALALAVIITSYNIWN MDPGYDSIIYRMTNQKIRMD

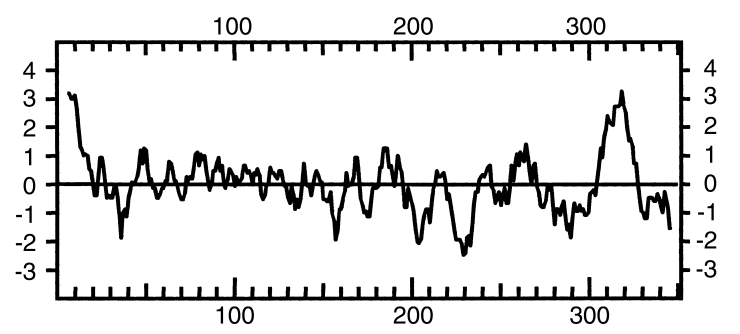

\section{Figure 1}

Nucleotide and amino acid sequence of N14F. (a) The nucleotide sequence is numbered on the right. The ATG of GCACCATGG is assigned as codon 1 on the basis of its close match to the C/GCACCATGG Kozak consensus sequence for optimal initiation of translation in eukaryotic cells. An in-frame TGA stop codon is located 858 nucleotides before the AATAAA cleavage and polyadenylation sequence, followed by the poly $(A)^{+}$sequence 15 nucleotides after the AATAAA. (b) The amino acid numbering begins with the first methionine of the longest open reading frame. The hydropathy profile of the deduced amino acid sequence of the N14F computed according to Kyte and Doolittle hydropathicity analysis is shown in the lower panel. The region with hydropathic index consistent with formation of a transmembrane spanning segment of 21 amino acids is boxed. Tyr 335, the amino acid most likely to be phosphorylated, is underlined.

amino acid sequence and the analysis of hydrophobicity of the translated protein (30) predicts that the protein has two hydrophobic regions, one located in the amino terminus from amino acids $1-16$, which likely represents a signal peptide, and another in the carboxy terminus from amino acids 306-326, which likely represents a transmembrane region (Figure $1 \mathrm{~b}$ ). Of the 24 amino acids of the cytoplasmic tail, Ser 337, Thr 343, Tyr 335, and Tyr 340 represent possible sites for regulatory phosphorylation, of which Tyr 335 appears to be the most likely phosphorylated site (NetPhos 2.0 prediction). The predicted structure of this protein was characterized by the absence of a N-linked glycosylation site, a pI of 5.76, no PEST (proline, glutamic acid, serine, and threonine) sequence, and an estimated half-life of 30 hours (PSORT II prediction).

In vitro translation and coprecipitation of the FLAG receptor with renin. The construct N14F-FLAG was translated in vitro using a rabbit reticulocyte lysate system and labeled with ${ }^{35}$ S-methionine. Analysis by SDS-PAGE and fluo- rography showed one band at the expected molecular weight of $39 \mathrm{kDa}$ (Figure 2a, lane A). Prior to performing cell transfection, we tested the interaction of N14F with renin by coprecipitation experiments. The translated product labeled with ${ }^{35} \mathrm{~S}$-methionine was incubated with renin $(25 \mathrm{nM})$ for 2 hours at $37^{\circ} \mathrm{C}$, and the complexes precipitated with anti-renin $\mathrm{Ab}$. SDS-PAGE and fluorography analysis of the precipitate showed that the receptor was recovered in the precipitate, confirming that $\mathrm{N} 14 \mathrm{~F}$ was able to interact with renin (Figure $2 \mathrm{~b}$, lane $\mathrm{B})$. In the absence of renin, anti-renin $\mathrm{Ab}$ did not react with in vitro-translated receptor (Figure $2 b$, lane $C$ ) or by Western blot analysis (Figure 2c).

Renin binding and membrane expression of N14F protein by HMC cells transformed with N14F. Next, the identity of the cloned cDNA was demonstrated by stable transfection of immortalized fetal HMCs (28) that did not express N14F either by PCR using primers specific for N14F or by Northern blot analysis (not shown). Two clones of stable transformants, HMC2 and HMC4, were analyzed 


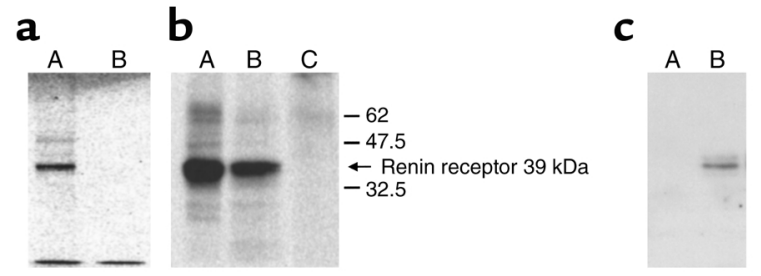

Figure 2

In vitro transcription/translation of N14F/FLAG protein and coprecipitation with renin. (a) N14F/FLAG fusion protein (lane A) or control empty vector (lane B) transcribed in vitro and labeled with ${ }^{35} \mathrm{~S}$-methionine are analyzed by SDS-PAGE and fluorography. (b) Coprecipitation of the N14F/FLAG fusion protein incubated with renin and immunoprecipitated with anti-renin $A b$. The proteins were eluted and analyzed by SDS-PAGE and flurography. Lane A: N14F/FLAG fusion protein immunoprecipitated with anti-FLAG agarose; lane B: elution of N14F/FLAG protein bound to renin; lane C: N14F/FLAG protein immunoprecipitated with anti-renin Ab. (c) Renin alone (lane A) was immunoprecipitated with $A b$ to the renin receptor and analyzed by Western blotting with anti-renin $A b$. Lane B: recombinant renin.

by binding assays. The binding of renin on transformed cells is saturable and characterized by a $K_{\mathrm{d}}$ of $5.0 \mathrm{nM}$ and a maximal binding site $\left(B_{\max }\right)$ of $2.8 \mathrm{fmol} / 100,000$ cells, corresponding to approximately 17,000 sites/cell for HMC2, and a $K_{\mathrm{d}}$ of $7.8 \mathrm{nM}$ and a $B_{\max }$ of 1.8 fmol/100,000 cells, approximately 13,000 sites/cell for HMC4. In contrast, HMC control cells do not display any specific renin binding (Figure 3a). Renin-specific binding to HMC2 cells was inhibited by an excess of cold prorenin $(100 \mathrm{nM})$, suggesting that the receptor also binds prorenin. In contrast, renin binding was not inhibited by an excess of other aspartyl proteases, such as pepsin and cathepsin $\mathrm{D}$, or modified by nonrelated proteins, such as hemoglobin, hepatocyte growth factor, or tissue-plasminogen activator (not shown). To further assess the membrane expression of the renin receptor on HMC2 cells we performed immunofluores- cence staining with $\mathrm{Ab}$ to the receptor and analysis by confocal microscopy. The results showed that the renin receptor was cell surface associated and that no staining could be detected in control cells transfected with empty vector (Figure $3 b$ ).

Increased catalytic efficiency of angiotensinogen cleavage by membrane-bound renin and prorenin. The kinetics of angiotensinogen cleavage by HMC 2 membrane-bound renin and renin in solution were compared. The results showed that the amount of Ang I generated by membrane-bound renin was much higher than that by renin in solution (Figure 4a). The double-reciprocal (Lineweaver-Burk) transformation of data resulted in $K_{\mathrm{m}}$ values of $1 \mu \mathrm{M}$ and $0.15 \mu \mathrm{M}$ for renin in solublephase and membrane-bound renin, respectively (Figure $4 b)$. From the slope of the individual double-reciprocal plots and the values of renin eluted from the membranes, the catalytic constant $\left(\mathrm{k}_{\text {cat }}\right)$ values were $2.4 \mathrm{~s}^{-1}$ and $1.4 \mathrm{~s}^{-1}$ with $0.5 \mathrm{nM}$ renin for solution phase and membrane-bound renin, respectively. For $1 \mathrm{nM}$ renin immobilized on the membranes or in solution, the $\mathrm{k}_{\text {cat }}$ values were $2.6 \mathrm{~s}^{-1}$ and $1.8 \mathrm{~s}^{-1}$ for solution-phase and membrane-bound renin, respectively. Therefore the catalytic efficiency of the reaction of renin with angiotensinogen measured by the ratio $\mathrm{k}_{\text {cat }} / K_{\mathrm{m}}$ was lower for renin in solution, 2.2 to $2.4 \mu \mathrm{M}^{-1} \mathrm{~s}^{-1}$, than for renin bound to the receptor, 9.3 to $11.2 \mu \mathrm{M}^{-1} \mathrm{~s}^{-1}$ (Figure $4 c)$. These results indicate that angiotensinogen cleavage by membrane-bound renin is five times more efficient than by renin in solution. When membranes from HMC control cells were tested for renin binding, an elution of bound renin, the amount of renin eluted from HMC membranes, was under the limit of detection of the renin antigen assay, precluding the comparison of angiotensinogen conversion by HMC membranebound renin to renin in solution. In addition, Ang I generation was identical in buffer and in the presence of 10 $\mu \mathrm{g}$ of HMC membrane (not shown), indicating that phospholipids alone, in the absence of receptor, do not

b

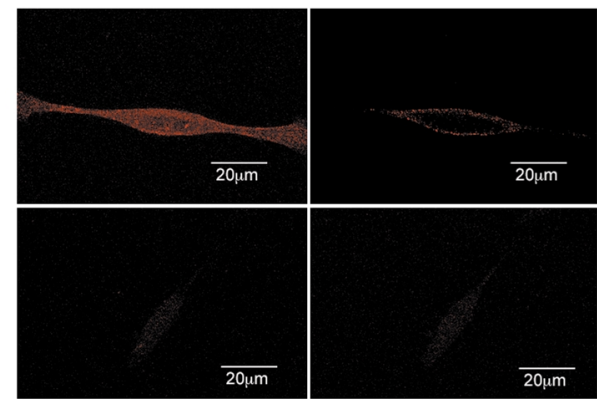

\section{Figure 3}

\section{a}

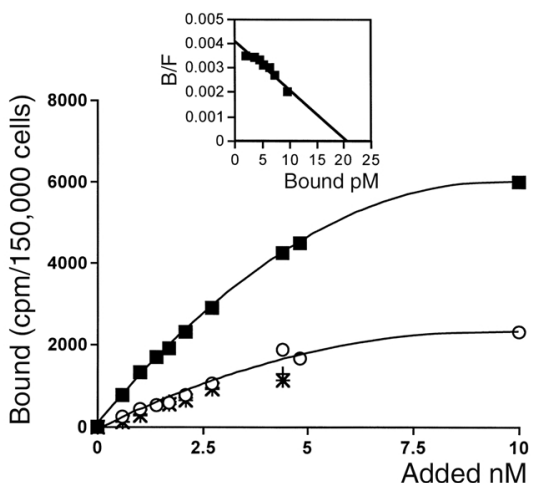

Membrane expression of N14F protein and renin binding by HMC cells transformed with N14F. (a) Saturation of binding on the HMC clone 2 (HMC2) expressing the receptor (squares, total; circles, nonspecific) and on HMC control cells (+, total; $\times$, nonspecific). The nonspecific binding was determined in the presence of $100 \mathrm{nM}$ cold renin. Inset: Scatchard plot of the binding of renin to HMC2. (b) Immunofluorescence and confocal analysis of the expression of N14F on HMC2 cells stably expressing N14F (upper panel) and by HMC control cells transfected with empty vector (lower panel). The cells were stained with anti-receptor Ab (dilution 1:1,000) and with TRITC-conjugated secondary Ab. 

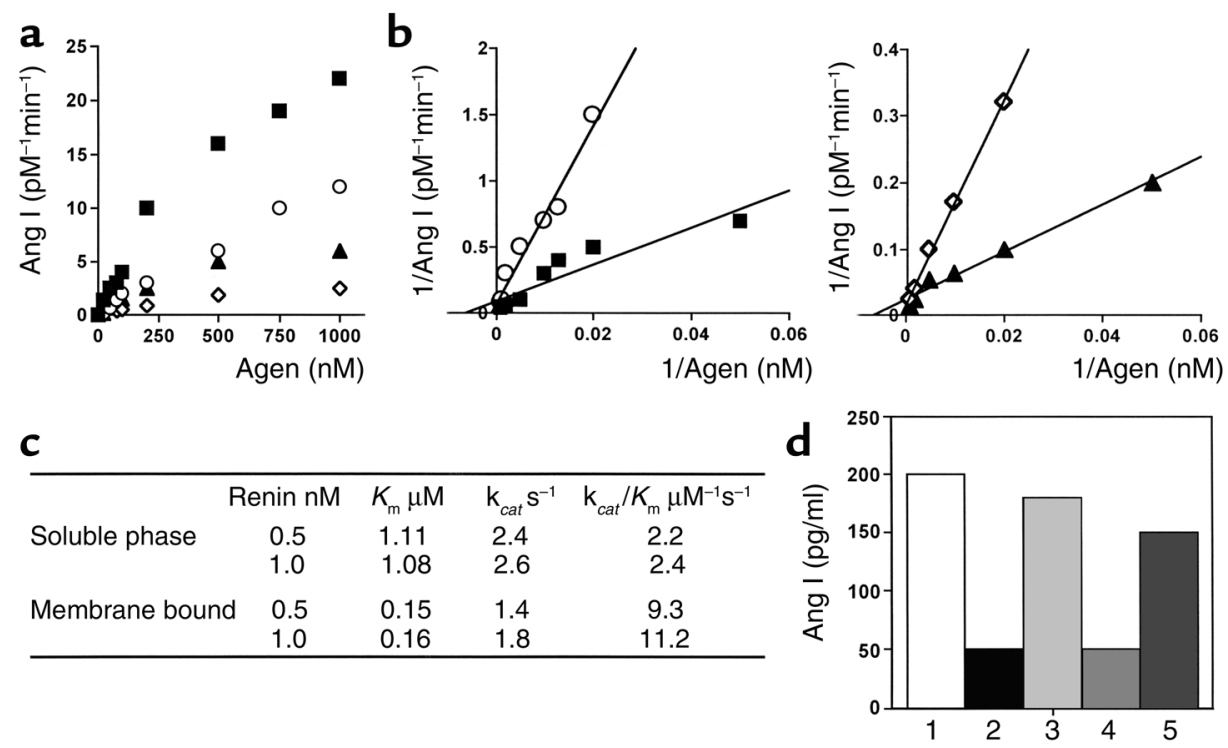

\section{Figure 4}

Ang I generation by soluble-phase and membrane-bound renin and prorenin. (a) Ang I generated by membrane-bound renin (squares, 1 $\mathrm{nM}$; triangles, $0.5 \mathrm{nM}$ ) and by renin in solution phase (circles, $1 \mathrm{nM}$; diamonds, $0.5 \mathrm{nM}$ ). (b) Lineweaver-Burk plots of $1 /$ Ang I generated vs. 1 /angiotensinogen (Agen) by $1 \mathrm{nM}$ renin bound to the membranes (squares) or in solution (circles), and by $0.5 \mathrm{nM}$ renin on membranes (triangles) or in solution (diamonds). (c) Kinetic parameters of Ang I production by renin. (d) Comparison of Ang I generated by $0.5 \mathrm{nM}$ renin and prorenin incubated with angiotensinogen (Agen) $1 \mu \mathrm{M}$ under different conditions. Bars 1, 2, and 3 are renin in solution, pH 5.7, for 1 hour; $\mathrm{pH} 7.4$ for 1 hour; and $\mathrm{pH} 7.4$ for 4 hours, respectively. Bars 4 and 5 are prorenin $\mathrm{pH} 7.4$ for 4 hours, in solution or membrane bound, respectively. Experiments were performed twice in duplicate, and the results represent the mean of the two experiments.

alter renin activity. However, we cannot exclude the possibility that, since renin is more closely apposed to membrane phospholipids, they may be important for the increase activity of renin. Next, we investigated the capacity of membrane-bound prorenin to activate angiotensinogen. The determination of recombinant prorenin antigen in our preparation of prorenin with the RIA Renin III generation kit, which uses an antirenin active site $A b$ as secondary $A b$, showed that about $25 \%$ of prorenin could be detected, indicating that the active site of prorenin was accessible in about $25 \%$ of the molecules. This prorenin preparation was used for binding to HMC2 membranes and for measuring the extent of Ang I generation as described. Prorenin bound to membranes was eluted by $\mathrm{pH} 3.5$ treatment and measured with the RIA Renin III generation kit. Acidification resulted in a total activation of prorenin (not shown). Accordingly, in the control experiments identical amounts of prorenin were incubated with angiotensinogen, in the absence of membranes. The results showed that at $\mathrm{pH}$ 7.4, little Ang I-generating activity was observed with $0.5 \mathrm{nM}$ prorenin in solution after 4 hours of incubation, compared with active renin under similar conditions. In contrast, when prorenin was immobilized on HMC2 membranes, the amount of Ang I generated was measurable and almost comparable to that generated by fully active renin in solution studied under similar experimental conditions (Figure 4d).

Cross-linking with renin and phosphorylation of the receptor. Immunoprecipitation of the receptor from transfected cells labeled with ${ }^{35} \mathrm{~S}$-methionine and with the poly- clonal anti-receptor $\mathrm{Ab}$ showed that the receptor has an apparent molecular weight of $45 \mathrm{kDa}$, greater than the in vitro translation product $(39 \mathrm{kDa})$, indicating that posttranslational modifications have occurred in the eukaryotic cell (Figure 5a, lane A). Our previous results have suggested a molecular weight of $70-80 \mathrm{kDa}$ for the receptor on primary human mesangial cells (21). Therefore, we performed cross-linking experiments of renin bound to transformed cells. The results showed the appearance of a 110- to 120-kDa band, confirming our previous study (Figure 5a, lane C). Precipitation of cell lysate with anti-FLAG Ab during the phosphorylation experiments confirmed a molecular weight of 45 $\mathrm{kDa}$ for the receptor as found by immunoprecipitation of ${ }^{35} \mathrm{~S}$-methionine-labeled cell lysate with the antireceptor $\mathrm{Ab}$. Renin stimulation induced a phosphorylation of serine and tyrosine residues of the receptor, but not of threonine (not shown). The phosphorylation of serine residues occurred more rapidly than for tyrosine and was already detectable after 3 minutes in the presence of renin, whereas the phosphorylation of tyrosine residues appeared after 10 minutes (Figure 5b, upper panel). No phosphorylation corresponding to a 45-kDa band could be observed in control cell lysate (Figure 5b, lower panel).

Intracellular $\left[\mathrm{Ca}^{2+}\right]$ and cAMP changes, MAP kinases ERK1(p44)/ERK2(p42) activation induced by renin. To further support the receptor function of the cloned renin receptor, we studied the effect of renin binding on $\left[\mathrm{Ca}^{2+}\right]$ concentration change, on cyclic AMP, and on MAP kinases ERK1(p44)/ERK2(p42) activation using 
two different techniques: Western blot analysis of total and active phosphorylated ERK1 and ERK2 and a MAP kinase activity assay. No changes in $\left[\mathrm{Ca}^{2+}\right]$ or in cyclic AMP could be evidenced after renin addition (Figure $6 a)$. On the contrary, renin addition induced a rapid activation of ERK1/ERK2 resulting in a twofold increase of active ERK1/ERK2 after $0.5 \min (P<0.05)$ and a three- to fourfold increase after 10 minutes and for at least 60 minutes (Figure 6b, left panel). The blot of total ERK1/ERK2 confirmed an even loading of the gels and the ratio of active-to-total ERK1/ERK2 was made using the NIH IMAGE program (Figure 6b, left). These data were confirmed by a MAP kinase activity assay (Figure 6b, left bottom). No activation of ERK1/ERK2 was observed in cells not expressing the receptor (Figure 6b, right panel).

Expression of renin receptor $m R N A$ in human adult tissues by Northern blot analysis. A single transcript of $2.4 \mathrm{~kb}$ was found in the brain, placenta, heart, liver, kidney, and pancreas. Because the amount of polyA $\mathrm{A}^{+} \mathrm{mRNA}$ immobilized on the membrane was adjusted for $\beta$-actin, the very strong signal observed in the brain, heart, and placenta indicates very high levels of expression of the receptor mRNA in those tissues. The mRNA of the renin receptor was barely detectable in lung and skeletal muscle (Figure 7).

Immunofluorescence staining and confocal microscopy on normal human kidney, heart, and placenta. Immunofluorescence staining of kidney cortex with the anti-receptor Ab showed labeling of glomeruli and vascular structures and no staining of the tubules and, at higher magnification, confirmed that the labeling was restricted to the mesangium (Figure 8a, left). The specificity of the staining was assessed by preincubation of the immune serum with the peptides (Figure 8a, right). Double-labeling with anti-CD31 Ab specific for endothelial cells and with anti-renin receptor $\mathrm{Ab}$ and analysis by confocal microscopy of kidney cortex showed that the renin receptor did not colocalize with CD31 in endothelial cells in glomeruli but was localized in the mesangial area. In kidney arteries, the renin receptor was not associated with the endothelium either (Figure 8, middle panel). To compare the vascular localization of the renin receptor in another tissue, we also studied the distribution of the receptor in the heart. The results showed that in coronary arteries, as in kidney arteries, the renin receptor did not colocalize with CD31 on endothelial cells but was found in the subendothelium (Figure 8, middle panel). To better localize the renin receptor in the subendothelium of kidney and coronary arteries, we performed a doublestaining with anti-receptor and anti-smooth muscle $\alpha$-actin $A b$. The results showed that the renin receptor colocalized with smooth muscle $\alpha$-actin, indicating that renin receptor was present on smooth muscle cells (Figure 8, lower panel). The absence of evidence for a colocalization of both renin receptor and smooth muscle $\alpha$-actin in normal glomeruli can be attributed to the absence of smooth muscle $\alpha$-actin expression by human mesangial cells in normal, noninflammatory glomeruli (31). Finally, we looked for a colocalization of renin and of the receptor in normal tissue. Placenta is known to secrete large amounts of renin and prorenin throughout gestation (7), and Northern blot analysis also showed abundant expression of the receptor in placenta. Immunofluorescence staining showed that the receptor was found in mature placenta, associated to vascular structures and to syncytiotrophoblast cells (Figure 9). In addition, staining of sequential section of placenta with renin $\mathrm{Ab}$ showed that renin and renin receptor had a similar pattern of distribution in arteries and in syncytiotrophoblast cells (Figure 9).

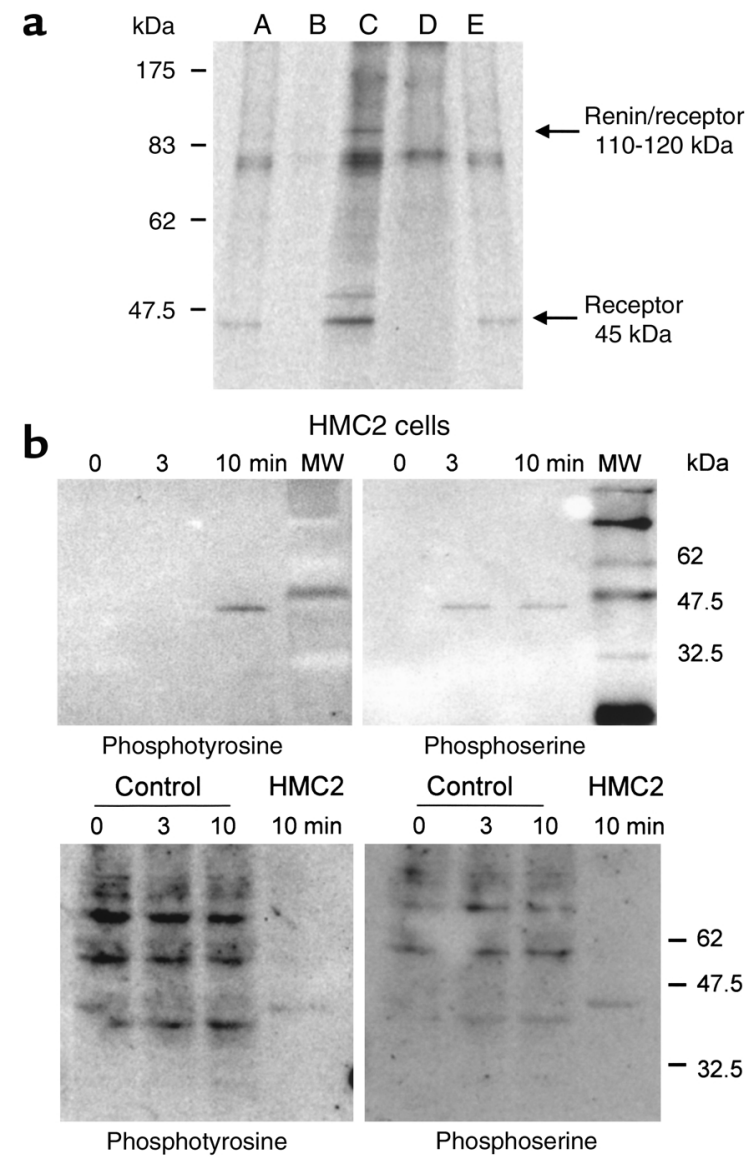

\section{Figure 5}

Cross-linking with renin and phosphorylation of the receptor. (a) $\mathrm{HMC}$ and control cells were labeled with ${ }^{35} \mathrm{~S}$-methionine, and the receptor was immunoprecipitated with anti-receptor $A b$ (lane $A$ and lane B for HMC and control cells, respectively) or after incubation with renin and cross-linking (lane $C$ and lane D for HMC and control cells, respectively). In lane E, HMC cells cross-linked in the absence of renin. (b) In the upper panel HMC2 cells were stimulated with renin in the presence of $100 \mathrm{nM}$ Captopril. The receptor was immunoprecipitated with anti-FLAG agarose, and the eluate was analyzed by Western blotting using Ab's to phosphotyrosine or to phosphoserine. In the lower panel control cells were stimulated with renin, and the cell lysate was analyzed by Western blotting using Ab's to phosphotyrosine or to phosphoserine. The right lanes of the two lower blots are the receptor immunoprecipitated from HMC cells stimulated by renin. 


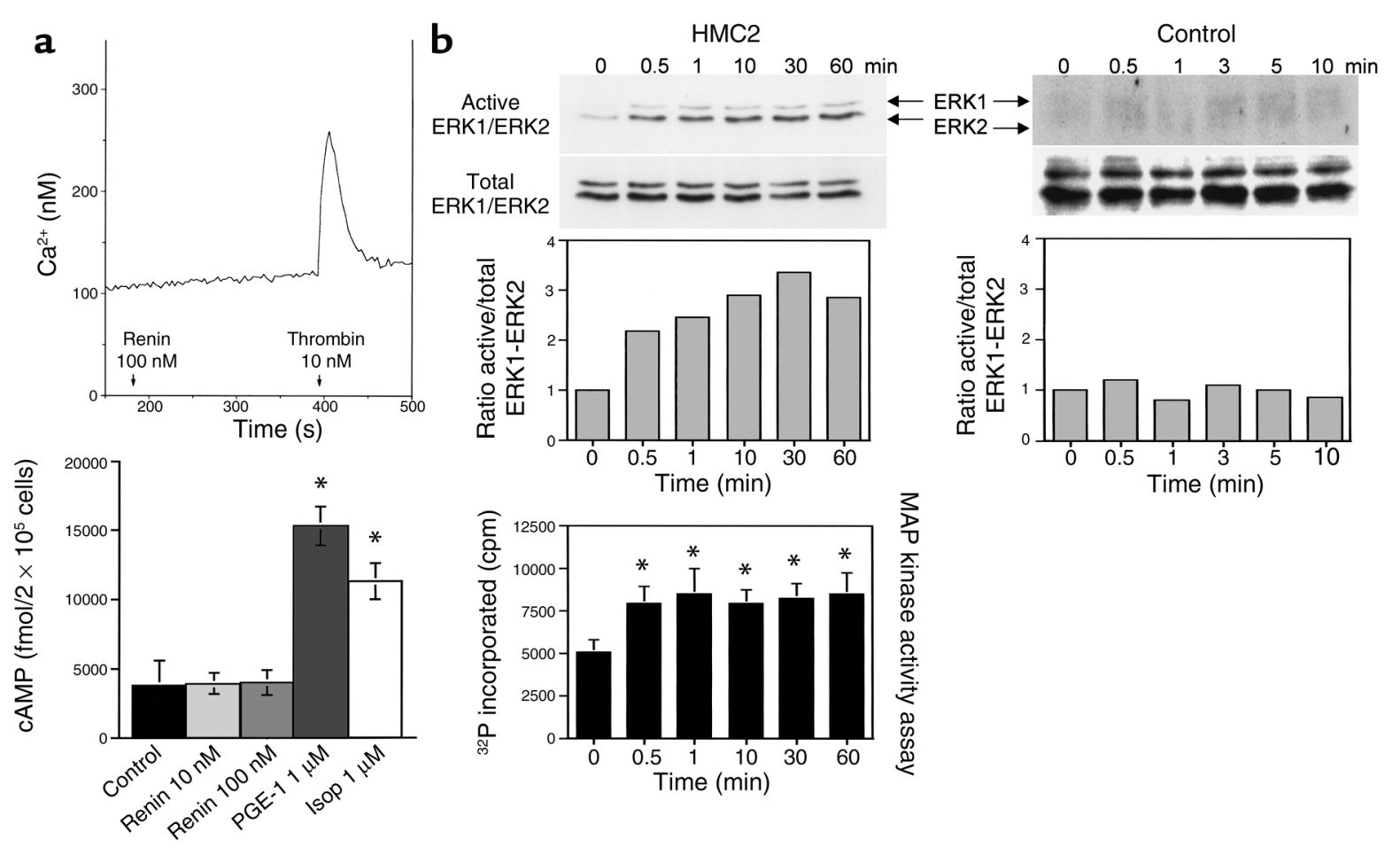

\section{Figure 6}

Intracellular calcium and cAMP changes, MAP kinases ERK1(p44)/ERK2(p42) activation induced by renin. (a) Cells expressing the receptor were stimulated by $100 \mathrm{nM}$ renin, and the intracellular calcium changes were analyzed by spectrofluorometry (top). Cell stimulation by human thrombin $(10 \mathrm{nM})$ was used as control. Analysis of intracellular cAMP changes by cells stimulated by $10 \mathrm{nM}$ renin and by $1 \mu \mathrm{M}$ PGE-1 or by $1 \mu \mathrm{M}$ isoproterenol (Isop), as positive controls (bottom). The results represent the mean \pm SD of two experiments performed in triplicate. ${ }^{*} P<0.05$ compared with basal value. (b) HMC2 cells (left panel) or control cells (right panel) were stimulated with renin in the presence of $1 \mu \mathrm{M}$ Losartan. At intervals, the cells were lysed and the lysate analyzed by Western blotting using Ab's to active or to total ERK1 and ERK2. The blots were scanned and the ratio of active, phosphorylated ERK1/ERK2 to total ERK1/ERK2 was plotted using the NIH IMAGE program. MAP kinase activity assay was performed on HMC2 renin-stimulated cells (left bottom). The results are expressed as ${ }^{32} \mathrm{P}$ incorporated and represent the mean $\pm \mathrm{SD}$ of two experiments performed in triplicate. ${ }^{*} P<0.05$ compared with basal value.

\section{Discussion}

This study reports, we believe for the first time, the existence of a functional receptor of renin. The evidence that $\mathrm{N} 14 \mathrm{~F}$ cDNA is identical to the receptor of renin is as follows: (a) The N14F protein expressed in vitro is able to bind renin in coprecipitation experiments; (b) cells transfected with N14F cDNA construct and expressing the protein bind renin with high affinity, and the binding is specific for renin and prorenin; (c) renin binding induces the activation of MAP kinases ERK1 and ERK2 associated with a phosphorylation of tyrosine and serine residues.

The localization of the receptor in the mesangium of glomeruli suggests that this receptor is the one we described on human mesangial cells in culture. In pri- mary mesangial cells (21) we have observed a molecular weight of $70-80 \mathrm{kDa}$ for the receptor, whereas the cloned renin receptor here is $45 \mathrm{kDa}$. This discrepancy may be explained by a dimerization of the receptor induced by renin binding as described for receptors of the tyrosine-kinase family, which are also single-transmembrane domain receptors (32), or a complex formation with another, yet-unidentified protein. Part of this clone was identical to the previously reported "M8-9," a truncated protein of $8.9 \mathrm{kDa}$ that copurified with a proton-ATPase of chromaffin granule membranes (33). While the sequencing of our N14F clone was completed, two identical cDNA sequences from human fetal brain and human hypothalamus appeared in Genbank (DKFZ p56400582, accession number AL049929.1 and

\section{Figure 7}

Expression of the receptor mRNA. Northern blot analysis. After hybridization of the human blot, a strong signal corresponding to a 2.4-kb mRNA band was detected in heart, brain, and placenta, a weaker signal was seen in liver, pancreas, and kidney. The mRNA of the receptor was hardly detected in lung and skeletal muscle. The amount of RNA on the membrane was adjusted so that $\beta$-actin hybridization is comparable in every lane.

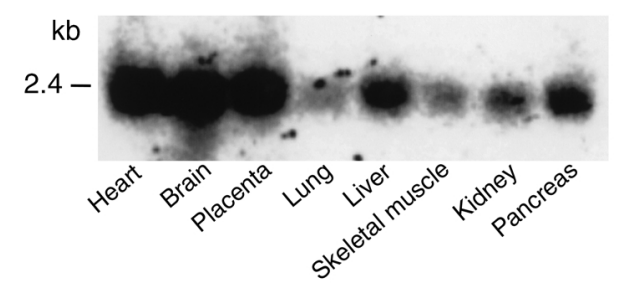


a
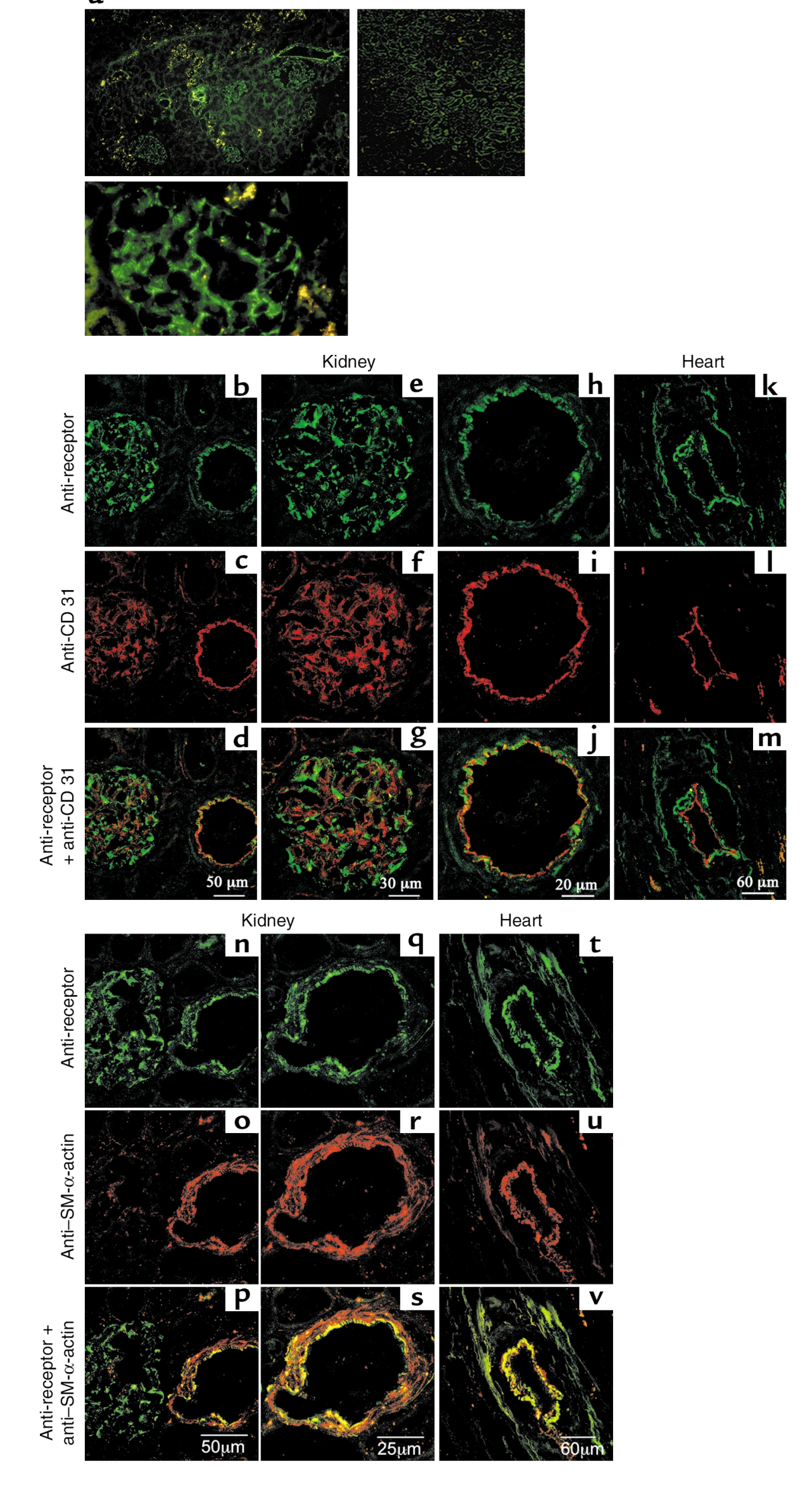

\section{Figure 8}

Expression of the renin receptor on human kidney and heart. (a) At the left, immuofluorescence staining of kidney cortex with anti-receptor $A b$ (upper panel magnification $\times 20$ ) and a glomerulus at higher magnification (lower panel, $\times 40$ ). Yellow staining is due to autofluorescence of degradation products in tubular cells. The immune serum was preincubated with the peptides (right). (b-m) Double-staining and analysis by immunofluorescence and confocal microscopy of kidney cortex labeled with anti-renin receptor $(\mathbf{b}$, $\mathbf{e}, \mathbf{h})$, anti-CD31 (c, f, i), and antireceptor plus anti-CD $31(\mathbf{d}, \mathbf{g}, \mathbf{j})$. $\mathbf{e}-\mathbf{g}$ represent the glomerulus in $\mathbf{b}-\mathbf{d}$, and $\mathbf{h}-\mathbf{j}$ represent the artery in $\mathbf{b}-\mathbf{d}$ at higher magnification. (k-m) A coronary artery labeled with anti-receptor, anti-CD31, anti-receptor plus anti-CD $31 \mathrm{Ab}$, respectively. (n-v) Double-staining and analysis by immunofluorescence and confocal microscopy of kidney cortex labeled with anti-renin receptor ( $\mathbf{n}$ and $\mathbf{q})$ or smooth muscle $\alpha$-actin Ab (SM- $\alpha$ actin; $\mathbf{o}$ and $\mathbf{r}$ ) and anti-receptor and anti-SM- $\alpha$-actin ( $\mathbf{p}$ and $\mathbf{s}$ ); $\mathbf{q}-\mathbf{s}$ represent the kidney cortex artery in panels $\mathbf{n}$ and $\mathbf{q}$ at higher magnification. (t-v) A coronary artery stained with anti-receptor, anti-SM- $\alpha$-actin, and anti-receptor plus anti-SM- $\alpha$ actin $A b$, respectively. 


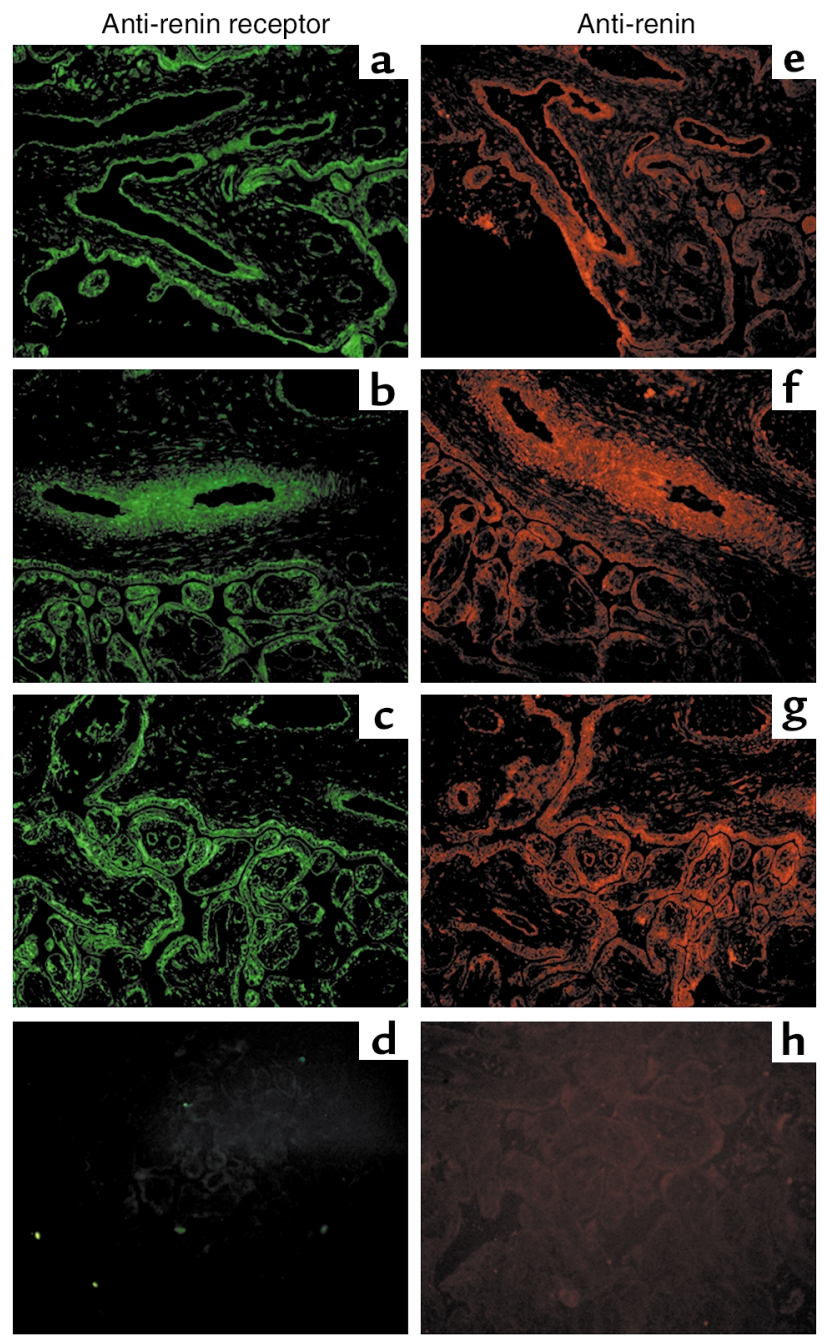

Figure 9

Expression and colocalization of renin and of the renin receptor in placenta. Sequential sections of placenta were stained with the $A b$ to the receptor and FITC-coupled secondary anti-rabbit $A b(\mathbf{a}-\mathbf{c})$ or with anti-renin $\mathrm{Ab}$ and Texas-red-coupled secondary $\mathrm{Ab}(\mathbf{e}-\mathbf{g})$. (d) FITC-secondary Ab alone. (h) TRITC-coupled secondary Ab alone. The receptor and renin have similar distribution in vascular structures and in syncytiotrophoblast cells.

AF248966), confirming the high level of expression of the receptor in the human CNS.

The physiological plasma concentration of renin is in the picomolar range, but it is admitted that in tissues, especially in interstitial fluids, the renin concentration may be 100 -fold greater. Since we found that the dissociation constant of the renin-receptor complex was in the nanomolar range, we postulated that it could not be considered as a binding protein responsible for retaining renin in the interstitium because only about $1 \%$ of the interstitial renin $(10 \mathrm{pM})$ would be bound by the receptor. Alternatively, it could function as an effective receptor. Therefore, we looked for $\left[\mathrm{Ca}^{2+}\right]$ change and for cyclic AMP and MAP kinases ERK1(p44)/ERK2(p42) activation. Our results showed that renin binding did not modify either intracellular calcium or cAMP, but provoked a rapid activation of the ERK1/ERK2 pathway, associated with a phosphorylation of serine and tyrosine residues. The presence of either an ACE inhibitor or an AT1 receptor antagonist during the incubation of transformed cells with renin confirms that these events are independent of a possible generation or action of Ang II. The pathway involved in the tyrosine phosphorylation of the receptor, the respective roles of serine and tyrosine phosphorylation in the receptor function, and the early phase of renin signal are actually under investigation.

We have shown that receptor-bound renin activates angiotensinogen with kinetics different from those observed for renin in solution and, in particular, we showed a reduction in the $K_{\mathrm{m}}$ for angiotensinogen from $1 \mu \mathrm{M}$ in solution to $0.15 \mu \mathrm{M}$ with receptor-bound renin. This $K_{\mathrm{m}}$ is significantly below the normal plasma concentration of angiotensinogen, approximately $1 \mu \mathrm{M}$ (29), suggesting that conversion of angiotensinogen by receptor-bound renin may be of physiological importance, especially in tissues in which the concentration of angiotensinogen is much lower than in plasma. We hypothesize that receptor-bound renin is able to activate angiotensinogen while it is actually bound to the cell surface and with higher efficiency than renin in solution. The slight decrease of $\mathrm{k}_{\text {cat }}$ (1.5-fold reduction) observed concomitantly might reflect the constraints imposed by the immobilization of renin on the receptor. The overall catalytic efficiency $\mathrm{k}_{\text {cat }} / K_{\mathrm{m}}$ increased four to five times, indicating that the cell surface is an important site for angiotensinogen activation. Taken together with the recent report of the existence of a vascular smooth muscle chymase (34), our results suggest that the smooth muscle cell surface may play an essential role in tissue generation of Ang II. The binding of renin to its receptor, thereby increasing angiotensinogen cleavage efficiency, would facilitate Ang I cleavage in Ang II by vascular smooth muscle chymase.

We also hypothesized that bound prorenin would activate angiotensinogen. Although our prorenin preparation was reactive against $A b$ 's to the active site of renin, suggesting that some molecules have an accessible active site, prorenin showed very little Ang I-forming activity when incubated at $\mathrm{pH} 7.4$ for 4 hours. However, the extent of Ang I generated by prorenin bound to membranes was comparable to the extent of Ang I generated by fully active renin under these experimental conditions. Whether the increase of the catalytic activity of membrane-bound prorenin should be attributed to the fraction of prorenin with an already exposed active site or to inactive prorenin that underwent conformational changes induced by receptor binding is an important issue to investigate in the near future. Supporting evidence for catalytically active prorenin in vivo, in the absence of prorenin cleavage, exists in the literature (35). Methot et al. generated double-transgenic mice expressing human angiotensinogen and a mutated, noncleavable human prorenin in the pituitary gland (35). These animals have elevated pituitary Ang I content in the 
absence of prorenin cleavage as shown by Western blot analysis, indicating that prorenin was enzymatically active even with the prosegment still in place.

Knockout mice for angiotensinogen, Ang converting enzyme, Ang II receptors, and nullizygotes for the renin gene, display low blood pressure and severe renal vascular lesions associated with high or low plasma renin concentrations (36-39). The vascular lesions have been attributed to the absence of Ang II during development, but these data do not exclude a role of renin in the pathogenesis of vascular lesions. Moreover, rats expressing the prorenin transgene exclusively in the liver suffer severe nephroangiosclerosis, cardiac and aortic hypertrophy, and liver fibrosis in the absence of hypertension (40). This observation suggests that the effects observed in vitro on the activation of ERK1/ERK2 pathway involved in cell hypertrophy and proliferation, as well as the cellular hypertrophy and the increase of PAI1 (21) synthesis, may be relevant in vivo.

In conclusion, our results show that renin receptor exerts dual effects. The renin receptor is able to trigger intracellular signal by activating the ERK1/ERK2 pathway, and it also acts as a cofactor by increasing the efficiency of angiotensinogen cleavage by receptor-bound renin, therefore facilitating Ang II generation and action on a cell surface. This novel concept may provide a new approach to a better understanding of the pathogenesis of vascular diseases associated with RAS activation.

\section{Acknowledgments}

We would like to thank Walter Fischli and Volker Breu for their constant intellectual and material support. We thank Oliver Nayler for helpful advice in the construction of the FLAG receptor. We also wish to thank Pierre Corvol, François Alhenc-Gelas, Eric Rondeau, and Raymond Ardaillou for stimulating discussions, Tam-Tam Guyenne for her advice on the Ang I assay, and Madeleine Delauche and Philippe Fontanges for expert technical assistance for confocal microscopy studies.

1. Sealey, J.E., White, R.P., Laragh, J.H., and Rubin, A.L. 1977. Plasma prorenin and renin in anephric patients. Circ. Res. 41:17-21.

2. Wolny, A., et al. 1997. Functional and biochemical analysis of angiotensin II forming pathways in the human heart. Circ. Res. 80:219-227.

3. Ardaillou, R. 2000. Angiotensin II receptors. J. Am. Soc. Nephrol. 10(Suppl. 11):S30-S39

4. Davisson, R.L., Oliviero, M.I., Coffman, T.M., and Sigmund, C.D. 2000. Divergent functions of angiotensin II receptors isoforms in the brain. J. Clin. Invest. 106:103-106.

5. Dostal, D.E., and Baker, K.M. 1999. The cardiac renin-angiotensin system. Conceptual, or regulator of cardiac function? Circ. Res. 85:643-650.

6. Siragy, H.M. 2000. AT(1) and AT(2) receptors in the kidney: role in disease and treatment. Am. J. Kidney Dis. 36(Suppl. 1):S4-S9.

7. Cooper, A.C., Robinson, G., Vinson, G.P., Cheung, W.T., and Broughton Pipkin F. 1999. The localization and expression of the renin-angiotensin system in the placenta throughout pregnancy. Placenta. 20:467-474.

8. Leung, P.S., Wong, T.P., Lam, S.Y., Chan, H.C., and Wong P.Y. 2000. Testicular hormonal regulation of the renin-angiotensin system in the rat epidedymis. Life Sci. 66:1317-1324.

9. Engeli, S., Negret, R., and Sharma, A.M. 2000. Physiology and pathophysiology of the adipose tissue renin-angiotensin system. Hypertension. 35:1270-1277.

10. Deinum, J., Derkx, F.H.M., Danser, A.H.J., and Schalekamp, M.A.D.H. 1990. Identification and quantification of renin and prorenin in the bovine eye Endocrinology. 126:1673-1682.

11. Wagner, J., et al. 1996. Demonstration of renin mRNA, angiotensinogen
mRNA, and angiotensin converting enzyme mRNA expression in the human eye: evidence for an intraocular renin-angiotensin system. Br.J. Ophtalmol. 80:159-163.

12. Tamura, T., Said, S., Harris, J., Lu., W., and Gerdes, A.M. 2000. Reverse modeling of cardiac myocyte hypertrophy in hypertension and failure by targeting of the renin-angiotensin system. Circulation. 102:253-259.

13. Guron, G., and Friberg, P. 2000. An intact renin-angiotensin system is a prerequisite for renal development. J. Hypertens. 181:23-137.

14. Schieffer, B., et al. 2000. Expression of angiotensin II and interleukine 6 in human coronary atherosclerotic plaques. Potential implications for inflammation and plaque instability. Circulation. 101:1372-1378.

15. Brown, N.J., and Vaughan, D.E. 2000. Prothrombotic effects of angiotensin. Adv. Intern. Med. 45:419-429.

16. Van Kesteren, C.A.M., et al. 1997. Mannose-6-phosphate receptor mediated internalization and activation of prorenin by cardiac cells. Hypertension. 30:1389-1396.

17. Admiraal, P.J., et al. 1999. Uptake and proteolytic activation of prorenin by cultured human endothelial cells. J. Hypertens. 17:621-629.

18. Maru, I., Ohta, Y., Murata, K., and Tsukada, Y. 1996. Molecular cloning and identification of $\mathrm{N}$-Acyl-D-glucosamine 2-epimerase from porcine kidney as renin-binding protein. J. Biol. Chem. 271:16294-16299.

19. Campbell, D.J., and Valentijn, A.J. 1994. Identification of vascular renin binding proteins by chemical cross-linking: inhibition of binding of renin by renin inhibitors. J. Hypertens. 12:879-890.

20. Sealey, J.E., et al. 1996. Specific prorenin/renin binding (proBP). Identification and characterization of a novel membrane site. Am. J. Hypertens. 9:491-502.

21. Nguyen, G., Delarue, F., Berrou, J., Rondeau, E., and Sraer, J.D. 1996. Specific receptor binding of renin on human mesangial cells in culture increases plasminogen activator inhibitor-1 antigen. Kidney Int. 50:1897-1903.

22. Nguyen, G., Bouzhir, L., Delarue, F., Rondeau, E., and Sraer, J.D. 1998. Evidence of a renin receptor on human mesangial cells: effects on PAI1 and cGMP. Nephrologie. 19:411-416.

23. Andreasen, P.A., Egelund, R., and Petersen, H.H. 2000. The plasminogen activation system in tumor growth, invasion, and metastasis. Cell Mol. Life Sci. 57:25-40.

24. Ellis, V., Behrend, N., and Dano, K. 1991. Plasminogen activation by receptor-bound urokinase. A kinetic study with both cell-associated and isolated receptor. J. Biol. Chem. 266:12752-12758.

25. Ossowski, L., and Aguirre-Ghiso, J.A. 2000. Urokinase receptor and integrin partnership: coordination of signaling for cell adhesion, migration and growth. Curr. Opin. Cell Biol. 12:613-620.

26. Coughlin, S.R. 2000. Thrombin signaling and protease-activated receptors. Nature. 407:258-264.

27. Mathews, S., et al. 1996. Recombinant human renin produced in different expression systems: biochemical properties and 3D-structure. Protein Expr. Purif. 7:81-91.

28. Banas, B., et al. 1999. Chemokine and chemokine receptor expression in a novel mesangial cell line. J. Am. Soc. Nephrol. 10:2314-2322.

29. Inoue, I., et al. 1995. A mutation of angiotensinogen in a patient with preeclampsia leads to altered kinetics of the renin-angiotensin system. J. Biol. Chem. 270:11430-11436.

30. Kyte, J., and Doolittle, R.F. 1982. A simple method for displaying the hydropathic character of a protein. J. Mol. Biol. 157:105-132.

31. Boukhalfa, G., Desmouliere, A., Rondeau, E., Gabbiani, G., and Sraer, J.-D. 1996. Relationship between alpha-smooth muscle actin expression and fibrotic changes in human kidney. Exp. Nephrol. 4:241-247.

32. Hubbard, S.R. 1999. Structural analysis of receptor tyrosine kinases. Prog. Biophys. Mol. Biol. 71:343-358.

33. Ludwig, J., et al. 1998. Identification and characterization of a novel 9.2-kDa membrane sector-associated protein of vacuolar proton-ATPase from chromaffin granules. J. Biol. Chem. 273:10939-10947.

34. Guo, B., et al. 2001. A novel vascular smooth muscle chymase is upregulated in hypertensive rats. J. Clin. Invest. 107:703-715.

35. Methot, D., Silversides, D.W., and Reudelhuber, T.L. 1999. In vivo enzymatic assay reveals catalytic activity of the human renin precursor in tissues. Circ. Res. 84:1067-1072.

36. Niimura, F., et al. 1995. Gene targeting in mice reveals a requirement for angiotensin in the development and maintenance of kidney morphology and growth factor regulation. J. Clin. Invest. 66:2947-2954.

37. Esther, C., et al. 1996. Mice lacking angiotensin converting enzyme have low blood pressure, renal pathology, and reduced male fertility. Lab. Invest. 74:953-965

38. Tsuchida, S., et al. 1998. Murine double nullizygotes of the angiotensin type $1 \mathrm{~A}$ and $1 \mathrm{~B}$ receptors genes duplicate severe abnormal phenotypes of angiotensinogen nullizygotes. J. Clin. Invest. 101:755-760.

39. Yanai, K., et al. 2000. Renin-dependent cardiovascular functions and reninindependent blood-brain barrier function revealed by renin-deficient mice. J. Biol. Chem. 275:5-8.

40. Véniant, M., et al. 1996. Vascular damage without hypertension in transgenic rats expressing prorenin exclusively in the liver. J. Clin. Invest. 98:1966-1970. 